\title{
Selective Diets for Dementia Disorders
}

Trevor Archer ${ }^{1,2^{*}}$ and Danilo Garcia ${ }^{1-4}$

${ }^{1}$ Department of Psychology, University of Gothenburg, Gothenburg, Sweden

${ }^{2}$ Network for Empowerment and Well-Being, Sweden

${ }^{3}$ Blekinge Centre of Competence, Blekinge County Council, Karlskrona, Sweden

${ }^{4}$ Institute of Neuroscience and Physiology, University of Gothenburg, Gothenburg, Sweden

*Corresponding author: Trevor Archer, Department of Psychology, University of Gothenburg, Box 500, S-405 30 Gothenburg, Sweden, Tel: +46 317864694 ; E-mail: trevor.archer@psy.gu.se

Received date: April 28, 2016; Accepted date: May 27, 2016; Published date: June 04, 2016

Copyright: ( 2016 Archer T, et al. This is an open-access article distributed under the terms of the Creative Commons Attribution License, which permits unrestricted use, distribution, and reproduction in any medium, provided the original author and source are credited.

\begin{abstract}
The global incidence of Alzheimer's disease (AD) is ever-increasing and all current therapies, when effective, remain only symptomatic. Diet, including fruit and vegetable juicing, nutritional supplements, and ketogenic supplements have been found to improve the condition of subjects presenting neurodegenerative disorders. Under various conditions, it is becoming increasing evident that a Mediterranean-type diet supplemented by olive oil and several different forms of physical exercise may improve global cognition. This type of selective diet that has been combined to be augmented by olive oil and soy isoflavone supplements is linked to potential improve memory and learning, as well as several other necessary daily activities, and several biomarkers of brain health and function. There is an ever-growing trend towards guidelines promoting a greater consumption of plant foodbased dietary patterns combined with limitations upon the consumption of animal-based food and a plethora of more-or-less specific guidelines have been formulated. Individual-centered strategies that combine interventions to improve physical, cognitive, and psychosocial functioning may offer improvements to lifestyle (e.g., change in diet) that promote cognitive health in the oldest-old.
\end{abstract}

Keywords: Diet selection; Vegetables; Meats; Supplements; Lifestyle; Cognition; Dementia

\section{Dementia Disorders}

Alzheimer's disease (AD) and other dementia conditions present a neurodegenerative panglial-neuronal disorder with long-standing brain hypometabolism, aberrations in both neuronal and astrocytic glucose metabolism, in lammation, hyperexcitability, and various types of dementia. he global incidence of $\mathrm{AD}$ is ever-increasing and all current therapies, when effective, remain only symptomatic. Lifestyle alterations seem to be a necessary ingredient of any therapy. For example, several disparities arising from sociodemographic evidence, including income inequality, and targeting interventions to improve depressive symptoms and vascular risk factors, including diabetes, may play an important role in preserving cognition among women who survive to $80+$ years of age. Cognitive decline or dementia is a debilitating problem of neurological disorder. It has been considered for quite some time that the so-called "Mediterranean diet" holds particular advantages for healthy brain aging [1-4], through preserved structural connectivity in older subjects [5], preservation of cognitive integrity [6] and actions against metabolic diverse disorders including cancer, pulmonary disease and cognition defects [7]. Another aspect of this type of diet is expressed by date palm fruits which offer a reliable source of dietary iber and are rich in total phenolics and natural antioxidants, such as anthocyanins, ferulic acid, protocatechuic acid and caffeic acid, all compounds providing a range of neuroprotective bene its. he APPsw/Tg2576 mouse model of AD displays age-related deterioration in cognitive performance as well as amyloid-beta (A $\beta)$ accumulation, and this laboratory preparation therefore offers an effective animal model for examining different mechanisms of accelerated brain aging and senescence through the perspectives of multiple biomarkers. In standard diet-fed transgenic APPsw]/Tg2576 mice marked cognitive impairments, increased anxiety-related behavior, and severe impairment in spatial learning ability, position discrimination learning ability and motor coordination were displayed in comparisons with wild-type on the same diet. Transgenic APPsw]/ Tg2576 mice fed $2 \%$ and $4 \%$ date supplementation at the age of 18 months evidenced lower levels of both $A \beta$ proteins in those date fruits supplemented groups than those mice without the diet supplement [8]. The neuroprotective advantages offered by the $4 \%$ date fruit-diet given to $\mathrm{AD}$ mice were markedly higher than $2 \%$ date fruit-diet supplementation. Curative treatment posits a major lacuna. Naringin and rutin represent a pair of dietary flavonoidsthat are natural flavonoid agents that are known to induce pleiotropic-type neuropharmacological effects with potential neuroprotective benefits. Their study evaluated these flavonoids for their potential to improve the most common form of episodic memory (memory of autobiographical events in relation to time, places etc.) in different, yet parallel, animal models assessing short-term and long-term memory, respectively.

Adequate nutrition and physical exercise interventions provide the two potential lifestyle modifiable factors that have accumulated considerable and focal interest for their potential in the prevention or management of this challenging disease $[9,10]$, with proper diet for the elderly as a modifiable risk factor [11]. The integration of longitudinal/ semi-longitudinal epidemiological data combined with biomarkers of disease, including brain imaging and morphological studies, and randomized controlled interventions are presenting further insights into progressive and subtle neurological changes associated with 
Page 2 of 4

dietary factors in individuals at risk for or living with AD. Neuroimaging techniques have been utilized to examine the effects on brain functional parameters and neuroanatomy, and assess the effects of dietary supplementations and nutritional patterns in relation to neurodegeneration and AD-related features [12]. Several dietary supplements have offered more-or-less promising benefits as observed both in the clinical reality and in the animal laboratory, including docosahexaenoic acid (DHA) [13], low-fat with metformin supplementation [14], moderate levels of seafood consumption [15], hazelnut (Corylusavellana L.) dietary supplement [16], creatine supplementation [17], ketogenic diet [18], dietary coconut which comprises medium-chain fatty-acids that may be converted to ketones easily [19], flavanols that are highly represented in cocoa extracts [20], and linalool which occurs in many natural oils [21]; all these potential dietary ingredients may either delay $\mathrm{AD}$ onset of even reverse its progress after symptoms have made their debut. An improved understanding of mechanisms involved in nutritional influences on $\mathrm{AD}$ risk and progression, such as oxidative stress and loss of neuronal membrane integrity, as well as the presence of associated disorders, including diabetes, obesity and metabolic syndrome [22], has offered a wider range and availability of interventional strategies. Berti et al. [23] have described how specific dietary nutrient patterns are associated with brain biomarkers of $\mathrm{AD}$ in cognitively normal individuals, suggesting that dietary interventions may exert a role in the prevention of $\mathrm{AD}$ by modulating $\mathrm{AD}$-risk through its effects on $\mathrm{A} \beta$ and associated neuronal impairment. Thus, the identified 'AD-protective' nutrient combination was linked to higher intakes of fresh fruit and vegetables, whole grains, fish and low-fat dairies, accompanied by lower intake of sweets, fried potatoes, high-fat dairies, processed meat and butter.

Madhavadas et al. [24] found that the supplementation of 'darkchocolate' reduced the hyperglycemia, inhibited the cholinesterase activity in the hippocampal tissue homogenates, and improved the cognitive performance in spatial memory-related Barnes maze task in aged rats. Increases in the cell volumes of neurons in the CA3 region of the hippocampus of the supplemented rats were obtained that accompanied the benefits of enhanced cognitive function, hippocampal cholinergic activity and corrections for metabolic disruptions. Furthermore, nutritional interventions that utilize antiinflammatory nutrients, e.g. cloves, ginger, rosemary, turmeric, etc, may be used to treat type- 2 diabetes, cardiovascular disorders and obesity, that may or may not be implicated in $\mathrm{AD}$ [25]. Hosono et al. [26] have observed that a four-month dietary treatment of $\operatorname{Tg} 2576$ mice, that have a normal development but exhibit age-related cognitive impairments, with an arachidonic acid- or a docosahexaenoic acidcontaining diet prevented expressions memory impairment at 13 months-of-age through the alteration of amyloid- $\beta$ protein precursor (A $\beta \mathrm{PP}$ ) processing (see also Hosono et al. [27] Teng et al. [28]). There is a great variation in the availability of dietary supplements: Huperzine A, which is available as a dietary supplement in the United States, is an example of an acetylcholinesterase inhibitor extracted from Huperzia Serrata, a firmoss, which has been applicable for a wide range of diseases in traditional Chinese medicine for fever and neuroinflammatory infections. The potential dietary supplement induces its protective effects mainly via $\alpha 7 \mathrm{nAChRs}$ and $\alpha 4 \beta 2 \mathrm{nAChRs}$, thereby producing a potent anti-inflammatory response by decreasing IL- $1 \beta$, TNF- $\alpha$ protein expression, and suppressing transcriptional activation of NF- $\mathrm{kB}$ signaling [29]. Yamakawa et al. [30] studied the effects of anthocyanoside extracts (Vaccinium myrtillus anthocyanoside (VMA)), occurring in all tissues of higher plants, obtained from bilberry on the in vitro progression of $\mathrm{A} \beta$ fibril formation with the in vivo effects of this compound on $\mathrm{AD}$ pathogenesis; they belong to a putatively 'parent' class of 'stem' molecules, the flavonoids. The treatment diet containing 1\% Vaccinium myrtillus anthocyanoside prevented the cognitive degeneration accompanied by an increased aggregate deposition of insoluble deposits in AD mice compared with mice raised on a control diet. Stress induced within metabolic processes within laboratory environments through recourse to a highfat diet combined low-dose injection of streptozotocin (exposure to nitrosamine) before the appearance of senile plaques and cardiovascular-related neuro-inflammatory outbursts in APP/PS1 transgenic mice [31,32]. Yeh et al. [33] found that streptozotocininduced peripheral metabolic stress contributed to vascular inflammation and astrocyte reactivity in the parenchyma and may impair activity of daily living skill and cerebral glucose metabolism in APP/PS1 mice. Diets that retain anti-inflammatory capabilities of regulating the synthesis and activity of inducible nitric oxide synthase under high-glucose levels, such as a glabridin supplement, may offer an anti-inflammatory protective agency in diabetes-related vascular dysfunction and disorders linked to AD [34]. Finally, it has been shown that markedly enhanced levels of cytokines linked to proinflammation, IL-1 $\beta$, IL-2, IL-3, IL-4, IL-5, IL-6, IL-9, IL-10, TNF- $\alpha$ and Eotaxin activity, were reduced through the dispensation of an array of dietary supplements/food composed from pomegranates, figs, or dates to transgenic APPsw]/Tg2576 mice [35]. Furthermore, putative delays in the formation of senile plaques, as indicated by a decreasing tendency of brain $A \beta 1-40$ and $A \beta 1-42$ contents, were observed in these laboratory mice.

\section{Conclusion}

The prevailing trend for cognitive-behavioral and neural longevity continues towards diets based upon vegetable-fruit produce rather than meat produce. Remarkably however, the dietary patterns selected and characterized by the alternate Mediterranean diet score, the Healthy Eating Index-2010, the Alternate Healthy Eating Index 2010, or the Dietary Approach to Stop Hypertension dietary scores were observed not to be linked with cognitive decline observed in older women that were investigated for over several-year periods [36]. Adherence to a healthy dietary pattern did not modify the risk for cognitive decline in women with hypertension. While this result does not necessarily confound the essential role of diet in aging, it does imply that a greater stringency in decisions regarding 'appropriate' or 'inappropriate' diets is warranted. In this context, one provocative question is whether or not one may facilitate and empower individuals to make self-directed choices to improve their diet. For instance, maladaptive behavior or destructive coping strategies (e.g., lack of physical exercise, smoking and drinking), may alter bodily functions that can have a significant impact on structural integrity of the body, for example, obesity or inactiveness resulting in cardiovascular diseases or type II diabetes [37]. This type of maladaptive behavior is related to, besides genetic factors, the person's inability to make self-directed choices with regard to her/his health show that individual differences in personality, lifestyle, and stress account for large prevalence of mortality from physical disorders in the USA). Fortunately, personcentered approaches that combine interventions to improve physical, cognitive, and psychosocial functioning promote sustainable personality development [38]. In other words, biopsychosocial interventions are needed in order to motivate individuals to choose an appropriate diet. 


\section{Conflict of Interest}

Dr. Danilo Garcia is the Director of the Blekinge Center of Competence, which is the Blekinge County Council's research and development unit. The Center works on innovations in public health and practice through interdisciplinary scientific research, personcentered methods, community projects, and the dissemination of knowledge in order to increase the quality of life of the habitants of the county of Blekinge, Sweden.

\section{References}

1. Gu Y, Brickman AM, Stern Y, Habeck CG, Razlighi QR, et al. (2015) Mediterranean diet and brain structure in a multiethnic elderly cohort. Neurology 85: 1744-1751.

2. Gu Y, Honig LS, Schupf N, Lee JH, Luchsinger JA, et al. (2015b) Mediterranean diet and leukocyte telomere length in a multi-ethnic elderly population. Age (Dordr) 37: 24.

3. Huhn S, Kharabian Masouleh S, Stumvoll M, Villringer A, Witte AV (2015) Components of a Mediterranean diet and their impact on cognitive functions in aging. Front Aging Neurosci 7: 132.

4. Lehert P, Villaseca P, Hogervorst E, Maki PM, Henderson VW (2015) Individually modifiable risk factors to ameliorate cognitive aging: a systematic review and meta-analysis. Climacteric 18: 678-689.

5. Pelletier A, Barul C, Feart C, Helmer C, Bernard C, et al. (2015) Mediterranean diet and preserved brain structural connectivity in older subjects. Alzheimers Dement 11: 1023-31.

6. Safouris A, Tsivgoulis G, Sergentanis TN, Psaltopoulou T (2015) Mediterranean Diet and Risk of Dementia. Curr Alzheimer Res 12 736-744.

7. Ginter E, Simko V (2015) Recent data on Mediterranean diet, cardiovascular disease, cancer, diabetes and life expectancy. Bratisl Lek Listy 116: 346-8.

8. Subash S, Essa MM, Braidy N, Awlad-Thani K, Vaishnav R, et al. (2015) Diet rich in date palm fruits improves memory, learning and reduces beta amyloid in transgenic mouse model of Alzheimer's disease. J Ayurveda Integr Med 6: 111-20.

9. Gustafson DR, Clare Morris M, Scarmeas N, et al. (2015) New Perspectives on Alzheimer's Disease and Nutrition. J Alzheimers Dis 46: 1111-1127.

10. Rege SD, Geetha T, Broderick TL, Babu JR (2016) Can Diet and Physical Activity limit Alzheimer's disease Risk?. Curr Alzheimer Res .

11. Yusufov M, Weyandt LL, Piryatinsky I (2016) Alzheimer's disease and diet: a systematic review. Int J Neurosci . [Epub ahead of print]

12. Pistollato F, Cano SS, Elio I, Vergara MM, Battino M, et al. (2015) The Use of Neuroimaging to Assess Associations Among Diet, Nutrients, Metabolic Syndrome, and Alzheimer's Disease. J Alzheimers Dis 48: 303-318.

13. Bascoul-Colombo C, Guschina IA, Maskrey BH, Good M, O'Donnell VB, et al. (2016) Dietary DHA supplementation causes selective changes in phospholipids from different brain regions in both wild type mice and the Tg2576 mouse model of Alzheimer's disease. Biochim Biophys Acta 1861: 524-37.

14. Asadbegi M, Yaghmaei P, Salehi I, Ebrahim-Habibi A, Komaki A (2016) Neuroprotective effects of metformin against AB-mediated inhibition of long-term potentiation in rats fed a high-fat diet. Brain Res Bull 121: 178-185.

15. Morris MC, Brockman J, Schneider JA, Wang Y, Bennett DA, et al. (2016) Association of Seafood Consumption, Brain Mercury Level, and APOE ÎM4 Status With Brain Neuropathology in Older Adults. JAMA 315: 489-97.

16. Bahaeddin Z, Yans A, Khodagholi F, Hajimehdipoor H, Sahranavard S (2016) Hazelnut and neuroprotection: Improved memory and hindered anxiety in response to intra-hippocampal AB injection. NutrNeurosci.
17. AliMohammadi M, Eshraghian M, Zarindast MR, Aliaghaei A, Pishva $\mathrm{H}$ (2015) Effects of creatine supplementation on learning, memory retrieval, and apoptosis in an experimental animal model of Alzheimer disease. Med J Islam Repub Iran 29: 273.

18. Cunnane SC, Courchesne-Loyer A, St-Pierre V, Vandenberghe C, Pierotti $\mathrm{T}$, et al. (2016) Can ketones compensate for deteriorating brain glucose uptake during aging? Implications for the risk and treatment of Alzheimer's disease. Ann N Y Acad Sci 1367: 12-20.

19. Fernando WM, Martins IJ, Goozee KG, Brennan CS, Jayasena V, et al. (2015) The role of dietary coconut for the prevention and treatment of Alzheimer's disease: potential mechanisms of action. Br J Nutr 114: 1-14.

20. Dubner L, Wang J, Ho L, Ward L, Pasinetti GM (2015) Recommendations for Development of New Standardized Forms of Cocoa Breeds and Cocoa Extract Processing for the Prevention of Alzheimer's Disease: Role of Cocoa in Promotion of Cognitive Resilience and Healthy Brain Aging. J Alzheimers Dis 48: 879-89.

21. Sabogal-Guequeta AM, Osorio E, Cardona-Gaemez GP (2016) Linalool reverses neuropathological and behavioral impairments in old triple transgenic Alzheimer's mice. Neuropharmacology 102: 111-20.

22. Su HY, Lee HC, Cheng WY, Huang SY (2015) A calorie-restriction diet supplemented with fish oil and high-protein powder is associated with reduced severity of metabolic syndrome in obese women. Eur J Clin Nutr 69: 322-328.

23. Berti V, Murray J, Davies M, Spector N, Tsui WH, et al. (2015) Nutrient patterns and brain biomarkers of Alzheimer's disease in cognitively normal individuals. J Nutr Health Aging 19: 413-423.

24. Madhavadas S, Kapgal VK, Kutty BM, Subramanian S (2016) The Neuroprotective Effect of Dark Chocolate in Monosodium GlutamateInduced Nontransgenic Alzheimer Disease Model Rats: Biochemical, Behavioral, and Histological Studies. J Diet Suppl 13: 449-60.

25. Gardener SL, Rainey-Smith SR, Martins RN, et al. (2015) Diet and Inflammation in Alzheimer's Disease and Related Chronic Diseases: A Review. J Alzheimers Dis 50: 301-334.

26. Hosono T, Mouri A, Nishitsuji K, Jung CG, Kontani M, et al. (2015) Arachidonic or Docosahexaenoic Acid Diet Prevents Memory Impairment in Tg2576 Mice. J Alzheimers Dis 48: 149-162.

27. Hosono T, Nishitsuji K, Nakamura T, Jung CG, Kontani M, et al. (2015) Arachidonic acid diet attenuates brain AB deposition in Tg2576 mice. Brain Res 1613: 92-99.

28. Teng E, Taylor K, Bilousova T, Weiland D, Pham T, et al. (2015) Dietary DHA supplementation in an APP/PS1 transgenic rat model of AD reduces behavioral and $\mathrm{AB}$ pathology and modulates $\mathrm{AB}$ oligomerization. Neurobiol Dis 82: 552-560.

29. Damar U, Gersner R, Johnstone J, Schachter S, Rotenberg A (2016) Huperzine $\mathrm{A}$ as a neuroprotective and antiepileptic drug: a review of preclinical research. Expert Rev Neurother 20: 1-10.

30. Yamakawa MY, Uchino K, Watanabe $\mathrm{Y}$, Adachi T, Nakanishi M, et al. (2016) Anthocyanin suppresses the toxicity of $A B$ deposits through diversion of molecular forms in in vitro and in vivo models of Alzheimer's disease. Nutr Neurosci 19: 32-42.

31. Li SQ, Yu Y, Han JZ, Wang D, Liu J, et al. (2015) Deficiency of macrophage migration inhibitory factor attenuates tau hyperphosphorylation in mouse models of Alzheimer's disease. J Neuroinflammation 12: 177.

32. Zhang Y, Yin F, Liu J, Liu Z, Guo L, et al. (2015) Geniposide attenuates insulin-deficiency-induced acceleration of B-amyloidosis in an APP/PS1 transgenic model of Alzheimer's disease. Neurochem Int 89: 7-16.

33. Yeh CW, Yeh SH, Shie FS, Lai WS, Liu HK, et al. (2015) Impaired cognition and cerebral glucose regulation are associated with astrocyte activation in the parenchyma of metabolically stressed APPswe/PS1dE9 mice. Neurobiol Aging 36: 2984-2994.

34. Essa MM, Subash S, Akbar M, Al-Adawi S, Guillemin GJ (2015) Longterm dietary supplementation of pomegranates, figs and dates alleviate neuroinflammation in a transgenic mouse model of Alzheimer's disease. PLoS One 10: e0120964. 
Page 4 of 4

35. Haring B, Wu C, Mossavar-Rahmani Y, Snetselaar L, Brunner R, et al (2016) No Association between Dietary Patterns and Risk for Cognitive Decline in Older Women with 9-Year Follow-Up: Data from the Women's Health Initiative Memory Study. J Acad Nutr Diet pii: S2212-2672(15)01815-8.

36. Cooper C (2013) From Stress to Wellbeing Volume 1: The Theory and Research on Occupational Stress and Wellbeing. Hampshire: Palgrave Macmillan.
37. Mokdad AH, Marks JS, Stroup DF, Gerberding JL (2004) Actual Causes of Death in the United States, 2000. JAMA 291: 1238-1245.

38. Cloninger RC (2004) Feeling Good: The Science of Well-Being. Oxford University Press, New York. 